\title{
A New Trophic Resource in the Diet of the Saw-tailed Curlytail, Leiocephalus carinatus (Squamata: Leiocephalidae) in Cuba
}

Anaisa Cajigas Gandia, Javier Torres, and Orlando J. Torres

Department of Animal and Human Biology, Faculty of Biology, University of Havana, Havana, Cuba (javiertorres@fbio.uh.cu)

$\mathrm{T}$ he Saw-scaled Curlytail (Leiocephalus carinatus) is a polytypic species naturally distributed in the Bahamas, Cuba, and the Cayman and Swan Islands, and which has been introduced in southeastern Florida (Henderson and Powell 2009). In Cuba, the species is widespread (Rodríguez-Schettino et al. 2013) and common, inhabiting rocky coasts, "mogotes" (peculiar limestone outcrops in western Cuba), and areas near human settlements around old buildings and roadsides (Rodríguez-Schettino 1999). This very cautious, diurnally active lizard exhibits an agility that belies its stocky build. In Cuba, males reach snout-vent lengths of 98.5-109.1 mm and females 90.9-100.9 mm (Rodríguez-Schettino 1999).

The trophic spectrum of this species is very wide. It feeds on many invertebrates, including insects and arachnids (Sampedro et al. 1979; Schoener et al. 1982; de Armas 1987; Fong and Garcés 2002), centipedes (Sampedro et al. 1979; de Armas 1987), crustaceans (de Armas 1987), and snails (Sampedro et al. 1979). It also consumes small vertebrates, and both cannibalism and heterospecific saurophagy have been reported (Schoener et al. 1982; de Armas 1987; Martínez and Rodríguez-Schettino 1987; Fong and Garcés 2002). In addition, these lizards consume vegetable material (Sampedro et al. 1979; Schoener et al. 1982; de Armas 1987; Fong and Garcés 2002), mainly fruits (Sampedro et al. 1979). Fong and Garcés (2002) found shed skin in the alimentary bolus, which is common for lizards (e.g., Perera 1985; de Armas 1987; Martínez and Fernández 1994; Sifers et al. 2001). Individuals also have been reported eating food for animals kept in the Havana Zoological Park and cooked chicken eggs (Rodríguez-Schettino 1999). Martínez and Moreno (2003) observed individuals "consuming sweets and remains of human food at tourist places, gardens, and yards of houses" (translated from Spanish), but they did not specify what type of food. Herein we report the exploitation of a new, human-made trophic resource.

On 20 February 2012, at $0931 \mathrm{~h}$ at the biological station in the Protected Area "Varahicacos" (23.19457 N, -81.15384
W; NAD27), on the Hicacos Peninsula, Matanzas Province, an adult male Leiocephalus carinatus was photographed feeding on discarded rice and black beans (a dish called congrí in Cuba; Fig. 1). The lizard approached the food carefully, with tail raised and curled, and apparently very much aware of the camera (Fig. 1A). Nevertheless, it quickly began to eat (Fig. 1B). Food recognition appeared initially to be by sight, possibly also by scent once at close range, and finally by taste and texture as indicated by use of the tongue, which was slightly protruded (Fig. 1A).

Arthropod abundance varies seasonally in tropical environments (i.e., more abundant during the rainy season; Wolda 1980; Tanaka and Tanaka 1982). This could result in limited energy availability for insectivorous reptiles, especially during the dry season when food and water are scarce, potentially triggering behaviors like those reported herein. However, we have no evidence of $L$. carinatus rejecting this kind of food during the rainy season. A more parsimonious explanation is that $L$. carinatus is an omnivorous, opportunistic species that exploits whatever resources are available in order to obtain the greatest amount of energy with the least possible expense. Consumption of immobile, energetically rich food like rice and beans would appear to be an ideal scenario, the probability of which is enhanced by the frequently reported association of this species with humans.

\section{Acknowledgements}

We thank Raimundo López-Silvero for information and photographs. We also thank the management of the protected area "Varahicacos," particularly its director Daniel Fajardo, for technical and logistical support.

\section{Literature Cited}

de Armas, L.F. 1987. Notas sobre la alimentación de Leiocephalus carinatus cayensis (Sauria: Iguanidae). Poeyana 350:1-7.

Fong, G.A. and G. Garcés. 2002. Composición y variación estacional de la dieta de Leiocephalus carinatus (Sauria: Iguanidae) en Santiago de Cuba, Cuba. Boletín de la Sociedad Herpetológica Mexicana 10(2):29-34. 

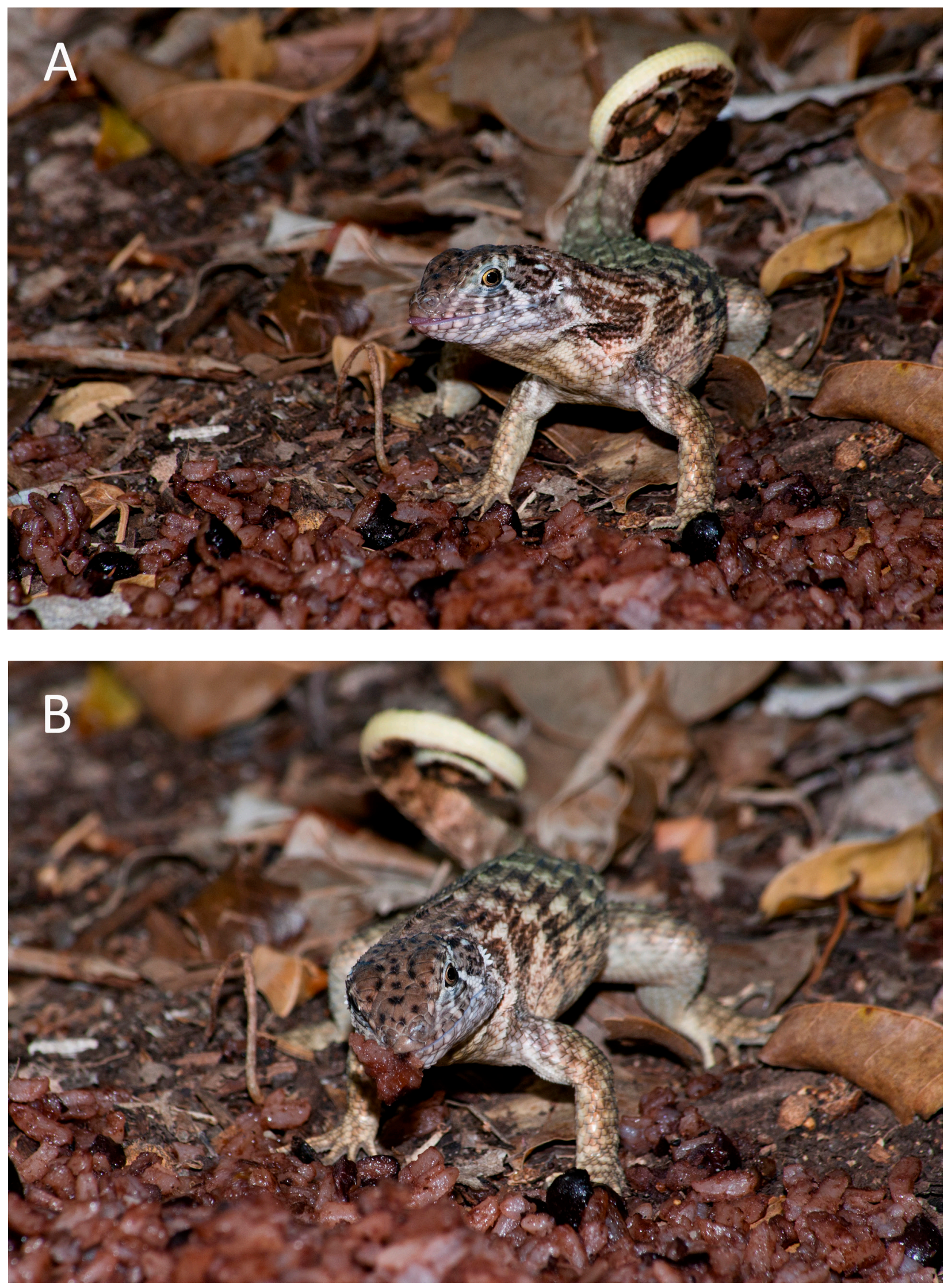

Fig. 1. An adult male Saw-scaled Curlytail (Leiocephalus carinatus) in Varahicacos, Cuba approaching (A) and eating (B) rice and black beans (a dish called congrí in Cuba). Photographs by Raimundo López-Silvero. 
Henderson, R.W. and R. Powell. 2009. Natural History of West Indian Reptiles and Amphibians. University Press of Florida, Gainesville.

Martínez, M. and I. Fernández. 1994. Hábitat y alimentación de Leiocephalus cubensis cubensis (Iguania: Tropiduridae) en una localidad de Ciudad de La Habana, Cuba. Ciencias Biológicas 26:21-30.

Martínez-Reyes M. and L. Rodríguez-Schettino. 1987. Canibalismo en Leiocephalus carinatus (Gray) (Sauria: Iguanidae). Miscelánea Zoológica 29:1-2.

Martínez-Reyes, M. and L.V. Moreno García. 2003. Lagartos habitantes de los suelos, pp. 90-97. In: L. Rodríguez-Schettino (ed.), Anfibios y Reptiles de Cuba. UPC Print, Vaasa, Finlandia.

Perera, A. 1985. Datos sobre la dieta de Cyclura nubila (Sauria: Iguanidae) en los alrededores de Cayo Largo del Sur, Cuba. Poeyana 291:1-12.

Rodríguez-Schettino, L. 1999. The Iguanid lizards of Cuba. University Press of Florida. Gainesville.

Rodríguez-Schettino, L. 1999. Systematic accounts of the species, pp. 115-123. In: L. Rodríguez Schettino (ed.), The Iguanid Lizards of Cuba. University Press of Florida, Gainesville.
Rodríguez-Schettino, L., C.A. Mancina, and V. Rivalta González. 2013. Reptiles of Cuba: Checklist and geographic distributions. Smithsonian Herpetological Information Service (144):1-96.

Sampedro Marín, A., V. Berovides Álvarez, and O. Torres Fundora. 1979. Hábitat, alimentación y actividad de dos especies de Leiocephalus (Sauria: Iguanidae) en dos localidades de la región suroriental de Cuba. Ciencias Biológicas 3:129139.

Schoener, T.W., J.B. Slade, and C.H. Stinsor. 1982. Diet and sexual dimorphism in the very catholic lizard genus Leiocephalus of the Bahamas. Oecologia 53:160-169.

Sifers, S.M., M.L. Yeska, Y.M. Ramos, R. Powell, and J.S. Parmerlee, Jr. 2001. Anolis lizards restricted to altered edge habitats in a Hispaniolan cloud forest. Caribbean Journal of Science 37:55-62.

Tanaka, L.K. and S.K. Tanaka. 1982. Rainfall and seasonal changes in arthropod abundance on a tropical oceanic island. Biotropica 14:114-123.

Wolda, H. 1980. Seasonality of tropical insects. Journal of Animal Ecology 49:277290. 